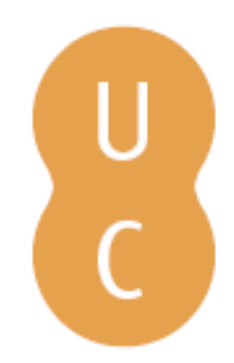

\title{
pombalina
}

\section{Questões de género e cidadania: reflexões breves sobre o poder emancipatório da educação}

\author{
Autor(es): $\quad$ Vieira, Cristina C.; Nunes, Maria Teresa Alvarez; Ferro, Maria Jorge \\ Publicado por: Imprensa da Universidade de Coimbra \\ URL \\ persistente: URI:http://hdl.handle.net/10316.2/41321 \\ DOI: $\quad$ DOI:https://doi.org/10.14195/978 98926 1326-0_32 \\ Accessed : $\quad$ 26-Apr-2023 10:39:56
}

A navegação consulta e descarregamento dos títulos inseridos nas Bibliotecas Digitais UC Digitalis, UC Pombalina e UC Impactum, pressupõem a aceitação plena e sem reservas dos Termos e Condições de Uso destas Bibliotecas Digitais, disponíveis em https://digitalis.uc.pt/pt-pt/termos.

Conforme exposto nos referidos Termos e Condições de Uso, o descarregamento de títulos de acesso restrito requer uma licença válida de autorização devendo o utilizador aceder ao(s) documento(s) a partir de um endereço de IP da instituição detentora da supramencionada licença.

Ao utilizador é apenas permitido o descarregamento para uso pessoal, pelo que o emprego do(s) título(s) descarregado(s) para outro fim, designadamente comercial, carece de autorização do respetivo autor ou editor da obra.

Na medida em que todas as obras da UC Digitalis se encontram protegidas pelo Código do Direito de Autor e Direitos Conexos e demais legislação aplicável, toda a cópia, parcial ou total, deste documento, nos casos em que é legalmente admitida, deverá conter ou fazer-se acompanhar por este aviso.






\title{
32. QUESTÕES DE GÉNERO E CIDADANIA: REFLEXÕ ES BREVES SOBRE O PODER EMANCI PATÓRIO DA EDUCAÇ ÃO
}

\author{
Cristina C. Vieira ${ }^{154}$ \\ Maria Teresa Alvarez Nunes 155 \\ Maria Jorge Ferro ${ }^{156}$
}

\section{Resumo}

Neste capítulo pretende-se discutir o papel da educação, considerada em sentido lato, na promoção da consciência crítica de quem aprende, mas também de quem ensina, seja qual for o contexto em análise, a respeito das aprendizagens de género, na sua maioria assentes em estereótipos que restringem a auto-determinação de cada pessoa nas suas escolhas e trajetos de vida. A reflexão apresentada resulta de experiências de formação contínua de docentes sobre as temáticas de género, educação e cidadania, na Faculdade de Psicologia e de Ciências da Educação da Universidade de Coimbra, Portugal, durante

${ }^{154}$ Faculdade de Psicologia e de Ciências da Educação da Universidade de Coimbra e Centro de Estudos Interdisciplinares do Século XX (CEIS 20), Portugal.

155 Centro de Estudos das Migrações e Relações Interculturais (CEMRI), Universidade Aberta, Portugal.

156 Faculdade de Psicologia e de Ciências da Educação da Universidade de Coimbra, Portugal. 
um período de dois anos, tendo envolvido sete cursos e cerca de 100 participantes.

\begin{abstract}
In this chapter it is our intention to discuss the role of education, considered in a broad sense, in promoting critical awareness of the learner, but also of those who teach, no matter the context under analysis, about the appropriation of knowledge related to gender, mostly based on stereotypes that restrict self-determination of each person in their decisions and life paths. Such reflection results from continuing education experiences of teachers on issues related to gender, education and citizenship, in the Faculty of Psychology and Sciences of Education, University of Coimbra, Portugal, for a two-year period, involving seven courses and about 100 participants.
\end{abstract}




\section{Introdução}

A educação, entendida em sentido lato, é o recurso mais importante de uma sociedade para fomentar mudanças positivas, condizentes com os valores amplamente partilhados de cidadania, qualquer que seja a idade de quem aprende, a modalidade de ensino, ou o contexto onde essas aprendizagens são efetuadas. Sabe-se também que a educação assume um papel fundamental na promoção da igualdade de oportunidades para todos/as, sendo necessário para isso que as diversas instâncias com responsabilidades educativas estejam concertadas entre si e sejam capazes de estar atentas e em sintonia quanto às necessidades específicas das pessoas que aprendem, à importância efetiva dos assuntos a debater e às características de quem ensina, como o faz e que conteúdos e recursos mobiliza.

O currículo da escolaridade obrigatória em Portugal não contempla de maneira explícita (de jure), e ao longo de todos os ciclos de ensino, um momento ou um espaço específico no horário letivo que convoque crianças e jovens para a discussão das questões de género ou de quaisquer outras formas de desigualdades de poder, que conduzem às assimetrias sociais, tudo isto apesar de o eixo estruturante da promoção da igualdade entre homens e mulheres, por via da educação formal, ser assumido como um princípio fundamental das políticas públicas em Portugal 157.

Há recomendações oficiais para a introdução destes conteúdos, no âmbito da educação para a cidadania, ao longo dos doze anos de escolaridade obrigatória em Portugal, disponíveis no sítio

157 Ver V Plano Nacional para a Igualdade, Género, Cidadania e Não-Discriminação (2014-2017), Resolução do Conselho de Ministros 103/103, disponível em https://www. cig.gov.pt/wp-content/uploads/2014/01/V_PL_IGUALD_GENERO.pdf 
oficial da Direcção-Geral da Educação (DGE), com o objetivo de levar a escola a "contribuir para a formação de pessoas responsáveis, autónomas, solidárias, que conhecem e exercem os seus direitos e deveres em diálogo e no respeito pelos outros, com espírito democrático, pluralista, crítico e criativo" (DGE, 2013, p. 1). Porém, a expressão 'linhas orientadoras'158, que é usada para sugerir o tratamento de tais assuntos, que são vistos como temas transversais à sociedade, ao pretender salvaguardar o respeito pela autonomia das escolas e dos/as docentes, faz desde logo crer que se trata, talvez, de conteúdos suplementares, que poderão ser ou não incluídos nas práticas letivas, ao longo do percurso escolar de alunos e alunas, anterior à entrada para a universidade ou à saída para o mundo do trabalho.

As quinze áreas temáticas de educação para a cidadania disponíveis são as seguintes ${ }^{159}$ : educação rodoviária; educação para o desenvolvimento; educação para a igualdade de género; educação para os direitos humanos; educação financeira; educação para a segurança e defesa nacional; educação para o voluntariado; educação ambiental e para a sustentabilidade; dimensão europeia da educação; educação para os media; educação para a saúde e a sexualidade; educação para o empreendedorismo; educação do consumidor; educação intercultural; e educação para o risco. Algumas têm inclusive referenciais já elaborados, bem como são disponibilizados documentos de referência, que constituem excelentes recursos para os/as docentes que queiram trabalhar as temáticas mencionadas em sala de aula. Contudo, como se disse, as escolas têm autonomia para incluir, ou não, estes tópicos no seu projeto educativo e o corpo docente é livre de escolher se pretende frequentar, ou não,

158 Documento para consulta disponível em: http://www.dge.mec.pt/sites/default/files/ECidadania/educacao_para_cidadania_linhas_orientadoras_nov2013.pdf .

159 Consultar: http://www.dge.mec.pt/areas-tematicas. 
ações de formação especialmente desenhadas para a exploração de diferentes dimensões da cidadania que podem considerar-se primordiais para a experiência docente, em particular, e para a vivência humana, em geral.

Não havendo aqui espaço para debater todas as áreas temáticas fundamentais que poderiam ser elencadas no âmbito da educação para a cidadania, este capítulo é dedicado a breves reflexões sobre o poder emancipatório que a educação de alunos e alunas e a formação inicial e contínua de docentes poderá ter para quem aprende e para quem ensina, na desconstrução de aprendizagens formais ou informais eivadas de estereotipias de género, prejudiciais a ambos os sexos, muitas vezes veladas, silenciosas ou mascaradas por uma aparente contemporaneidade.

Dedica-se o primeiro ponto do capítulo a uma clarificação conceptual das expressões sexo e género e à apresentação de conceitos-chave propostos por cientistas de inspiração feminista, o que se revela indispensável, em nosso entender, para uma leitura clarividente deste trabalho. As reflexões apresentadas no segundo ponto derivam sobretudo da experiência de duas das autoras como dinamizadoras de ações de formação acreditadas para docentes, sobre género, educação e cidadania, por eles e elas frequentadas em regime voluntário e horário pós-laboral, e que implicaram trabalho presencial e autónomo (nas escolas, com alunos e alunas de diferentes idades), por um período de dois meses em cada um dos sete grupos que tomamos como referência, entre 2013 e 2015, num total de cerca de uma centena de participantes. Estes cursos não conferentes de grau foram oferecidos pela Faculdade de Psicologia e de Ciências da Educação da Universidade de Coimbra, com o apoio da Comissão para a Cidadania e Igualdade de Género (CIG), que é um organismo do poder central diretamente dependente da Presidência do Conselho de Ministros. 


\section{Sexo e género: das categorias biológicas às aprendizagens sociais}

A nossa experiência como docentes e como formadoras de pessoas adultas - docentes e outros/as profissionais - em questões relativas à chamada igualdade de género faz-nos dedicar algumas linhas deste capítulo à necessária distinção entre os conceitos de sexo e de género, que tendem a ser erradamente usados como sinónimos. Seguindo autoras clássicas neste domínio (e.g., Oakley, 1972; Scott, 1986), o termo sexo deve ser usado para nos referirmos à categoria sexual dos indivíduos - sexo masculino ou sexo feminino - determinada pelos cromossomas sexuais. O genótipo traduz-se exteriormente em características fenotípicas que costumam, na grande maioria dos casos, justificar esta divisão dicotómica relativa à forma do corpo e dos órgãos genitais.

O termo sexo neste contexto deve, por isso, ser utilizado para descrever, por exemplo, uma amostra em termos estatísticos (estatísticas desagregadas por sexo), para identificar as pessoas em termos de categorias biológicas, não pressupondo, no entanto, características psicológicas (ou físicas), aptidões ou outros aspetos mais identitários de cada sujeito, dada a miríade de possibilidades de desenvolvimento humano. Tal como Simões (1990) considerou a idade uma variável vazia, para se referir ao fraco poder explicativo deste indicador na compreensão do comportamento humano, também consideramos, neste enquadramento, o sexo como tal, quer pela variabilidade intraindividual, quer pela interindividual. A primeira refere-se ao reconhecimento de que cada pessoa se desenvolve de maneira diversa - e em ritmos assíncronos - em diferentes domínios (físico, cognitivo, afetivo, identitário, social, moral, etc.), e a segunda remete-nos para o reconhecimento das diferentes formas de ser e de estar em sociedade, todas elas válidas e reconhecidas, desde que se rejam pelos princípios fundamentais de cidadania da vida democrática. 
Por seu turno, o termo género, nunca podendo ser expresso no plural, deve ser entendido como uma grelha de leitura da realida$d e$, na medida em que ele foi trazido para as Ciências Sociais, nos anos 60 do século XX (Neves, 2015) para desfazer a visão essencialista de que de uma pessoa do sexo masculino se devem esperar certos atributos, interesses e competências, e de uma pessoa do sexo feminino se devem esperar outros, habitualmente vistos como opostos e tendencialmente complementares, ainda que o feminino tenda a aparecer simbolicamente como subordinado ao masculino. Nas palavras de Amâncio (2002):

O fundamental na diferenciação entre o masculino e o feminino não são os atributos que, aparentemente, os distinguem (...) mas sim o facto dos conteúdos que definem a masculinidade estarem confundidos com outras categorias supra-ordenadas, como a de pessoa adulta, enquanto os significados femininos definem apenas um corpo sexuado. É neste processo de construção social que o simbolismo masculino se constitui como referente universal relativamente ao feminino que permanece marcado pela categoria sexual (p. 59).

Longe vão os tempos em que Parsons (1955, citado por Sprinthall \& Collins, 2011) falava da expressividade feminina e da instrumentalidade masculina ${ }^{160}$, mas a ciência dita mainstreaming ${ }^{161}$ e as

160 No seguimento desta visão assimétrica dos papéis sexuais, tende a esperar-se que os homens sejam mais competitivos, dominadores e independentes do que as mulheres, e que elas sejam mais dependentes, sensíveis e preocupadas com o bem-estar social do que eles. Estes estereótipos afetam, não apenas as reações das pessoas adultas, nas suas auto-avaliações e relações interpessoais, mas também por exemplo a forma como na família são educadas as crianças e adolescentes (Sprinthall \& Collins, 2011).

161 Referimo-nos aqui à visão nomotética (i.e., estabelecimento de leis gerais) de construção do conhecimento científico, fundada pelo paradigma positivista, muito assente ainda numa tentativa de estabelecimento de princípios explicativos do 
práticas quotidianas parecem continuar a evidenciar resquícios desse pensamento dual (Ostrouch-Kaminska \& Vieira, 2015), não apenas em contextos informais de aprendizagem, mas também em espaços organizados que conferem certificados ou diplomas académicos. Falar de género significa também falar de ordem (ou contrato) social aprendida em diferentes contextos (cf., Scott, 1986), que parece ser normativa e prescritiva de comportamentos e decisões individuais e grupais, para mulheres e também para homens, a qual convém desocultar, desconstruir, debater e reformular.

Para que a prossecução de medidas tendentes à promoção da igualdade de género se traduza numa efetiva equidade de acesso a bens e recursos, situamo-nos na linha do que defendeu Ollangnier (2014), de que um ato educativo sensivel ao género deve ser entendido, no limite, como a possibilidade de permitir às pessoas que aprendem, uma igualdade "de acesso às oportunidades da vida" (p. 223), analisando a informação à sua volta com as chamadas lentes de género, segundo a proposta de Bem (1993). Estas não são mais do que a tomada de consciência crítica de que o género continua a ser um eixo estruturante das relações sociais, e que o seu uso indevido - e sobretudo o seu esvaziamento pela colagem errónea ao termo sexo - apaga ou ofusca a heterogeneidade de características e potencialidades dos grupos formados com base nas categorias sexuais, sendo que há muitas mulheres e muitos homens - muitas formas de se ser e de se expressar - em todas as categoriais sociais.

O cruzamento das diferentes pertenças individuais e os possíveis processos discriminatórios subsequentes trouxeram para

comportamento humano, baseando as conclusões em grandes amostras, em dados quantitativos analisados por modelos matemáticos, em avaliações de confiabilidade baseadas em deduções a partir de postulados estatísticos, etc. Ninguém duvida, com toda a certeza, de que esta abordagem deixa muitas pessoas e grupos de fora - que ficam sem voz ou que são invisibilizados - desta tentativa de dar inteligibilidade aos fenómenos humanos. 
a discussão neste campo o conceito de interseccionalidade, que traduz basicamente a ideia de que para descrever uma pessoa é preciso recorrer a diversas categorias, sendo que cada um de nós é um ser único, em virtude da multiplicidade de combinatórias. As discriminações exercidas sobre pessoas e grupos tendem, por esse motivo, a ser múltiplas e as experiências de discriminação e de violação dos direitos humanos derivam de uma diversidade de relações desiguais de poder, assentes não apenas no sexo do indivíduo, mas também na etnia, na idade, na situação de deficiência, orientação sexual, situação de migrantes, entre outras (Khosla, 2008). Por conseguinte, qualquer atitude crítica que fomente o reconhecimento da pluralidade da vida humana obriga-nos "hoje a questionar permanentemente de que mulheres e de que homens falamos quando falamos de mulheres e homens, respetivamente" (Neves, 2015, p. 39), se o objetivo for assumir uma abordagem não excludente, onde o valor de todos/ as é respeitado e promovido.

Concordamos que "o surgimento e a utilização do conceito de género no campo académico estão intimamente ligados ao papel do feminismo e das lutas das mulheres pela igualdade e respetivos efeitos nos campos disciplinares, na universidade e na investigação científica" (Torres, Maciel, \& SantAna, 2015, p. 1). Isso não significa, no entanto, que falar de género seja falar de mulheres ou dos 'problemas das mesmas', pois a problematização do quotidiano traz necessariamente consigo o falar também de homens e das relações sociais entre os sexos. O género pode, por isso, ser um conceito muito rico do ponto de vista das potencialidades de análise da realidade que oferece, movido por uma dimensão ética e política fundamentada na teoria feminista (Neves, 2015). Leva-se assim quem ensina e quem aprende a desenvolver uma autonomia crítica 'não neutra' (ou cega), em termos de género, na construção do conhecimento sobre si, as outras pessoas e o mundo. 


\section{Género, cidadania e exercício da profissão docente: pode a educação ser emancipatória?}

Iniciamos este ponto com uma referência ao pensamento inspirador de Paulo Freire, sobre a intencionalidade do ato educativo, pois no seu entender ensinar exige a tomada de decisões (Freire, 2000), sendo que "a educação, especificidade humana [deve ser vista] como um ato de intervenção no mundo" (p. 122). De acordo com a visão crítica deste autor acerca da responsabilidade dos/as educadores/as na promoção de um conhecimento que tenha valor emancipatório para quem aprende, resultando isso quer da coerência do comportamento pedagógico (do docente) com os conteúdos ensinados, quer da valorização dos saberes de quem assume o papel de educando/a, adquiridos a partir das experiências quotidianas, Paulo Freire (2002) propõe aos docentes a prática do "desnudamento do contraditório" (p. 210). Nas suas palavras, "o cinismo não é a arma indicada para a reconstrução do mundo" (idem, ibidem), pelo que quem exerce a autoridade de ensinar deve pautar-se pela coerência, pela humildade e pela crença genuína naquilo que faz:

(...) qualquer que seja a visão político-pedagógica que tenhamos, como quer que a chamemos, pedagogia feminista, pedagogia radical, pedagogia crítica, pedagogia libertadora, pedagogia construtivista, precisamente porque progressista (...) teremos de buscar, por este ou por aquele caminho, a superação da contradição representada na incoerência (Freire, 2002, p. 211).

Fazendo uma analogia com as ideias de Paulo Freire, gostaríamos agora de partilhar algumas reflexões (e "falas") de docentes participantes em sete cursos de formação, com um total de $15 \mathrm{~h}$ presenciais e 15 horas de trabalho autónomo (durante o qual havia oportunidade para desenvolver atividades em sala de aula) cada. 
A realização destes cursos, na modalidade de oficina de formação, teve como objetivo levar os e as docentes a conhecer o Projeto dos Guiões de Educação Género e Cidadania ${ }^{162}$, da CIG $^{163}$, no âmbito do qual tinham sido publicados e disponibilizados em suporte de papel e online quatro guiões: um para o ensino pré-escolar ${ }^{164}$; um para o $1^{\circ}$ ciclo do ensino básico ${ }^{165}$ (primeiros quatros anos de escolaridade obrigatória); um para o $2^{\circ}$ ciclo $^{166}$ ( $5^{\circ}$ e $6^{\circ}$ anos); e um para o $3^{\circ}$ ciclo $^{167}\left(7^{\circ}, 8^{\circ}\right.$ e $9^{\circ}$ anos de escolaridade). Refira-se que a publicação do guião para o ensino secundário $\left(10^{\circ}, 11^{\circ}\right.$ e $12^{\circ}$ anos) deverá acontecer até final de 2016, dando cumprimento à medida 14 da área estratégica 2, sub-área 2.1. relativa à educação, ciência e cultura do V PNI ${ }^{168}$.

O critério para a seleção das inscrições era o facto de o/a docente estar a exercer naquele ano letivo a sua profissão, independentemente do ano de escolaridade em que lecionava ou a zona do país de onde era proveniente. Participaram nestes cursos não conferentes de grau e gratuitos docentes desde o nível pré-escolar ao ensino pré-universitário, de ambos os sexos, mas com uma predominância clara de profissionais do sexo feminino. No final de cada curso, para fins de avaliação, era pedida a cada participante uma reflexão final, anónima, sobre a utilidade da formação, as razões da inscrição e a intencionalidade de dar continuidade no futuro, com

162 Guiões em versão digital disponíveis para download em https://www.cig.gov. $\mathrm{pt} /$ documentacao-de-referencia/doc/cidadania-e-igualdade-de-genero/

163 Sitio oficial disponível em https://www.cig.gov.pt/

164 Disponível em https://www.cig.gov.pt/wp-content/uploads/2015/10/398_15_ Guiao_Pre_escolar.pdf

165 Disponível em http://www.arteset.com/NET_Guiao_1Ciclo_220915.pdf

166 Disponível em https://www.cig.gov.pt/wp-content/uploads/2013/12/guiao_ educa_2ciclo.pdf

167 Disponível em https://www.cig.gov.pt/wp-content/uploads/2016/07/3Ciclo_ Versao_Digital_FinalR.pdf

168 Disponível em https://www.cig.gov.pt/wp-content/uploads/2014/01/V_PL_ IGUALD_GENERO.pdf 
outras turmas e em diferentes anos de escolaridade, a algumas das atividades desenvolvidas.

Nesta sequência, foi para nós extremamente enriquecedor perceber que uma parte substancial dos/as participantes foi capaz de identificar, como primeiro grande indicador de satisfação, a tomada de consciência individual para a necessidade de auto-reflexão e de auto-avaliação, quer como docente, quer como cidadão ou cidadã, no exercício dos mais variados papéis sociais, dada a 'impregnação' (inconsciente) de estereotipias de género de algumas das suas práticas, dentro e fora da escola.

Passamos a transcrever algumas das reflexões deixadas pelos docentes, por escrito, no final das ações, onde fazem uma avaliação pessoal e deixam sugestões:

- "Esta formação faculta-nos conhecimentos e materiais muito úteis para o nosso desempenho diário e que nos possibilitam melhorar e enriquecer o ensino/formação dos jovens, consciencializando-os e sensibilizando-os para estas temáticas".

- "Deveria haver mais formações destas, indispensáveis para a prática de todos os docentes. Os Agrupamentos de Escolas deveriam estar mais envolvidos".

- "A minha sugestão está relacionada com a realização de um Guião de Educação Género e Cidadania para adultos, uma vez que trabalho por vezes com este público e também porque me parece importante e pertinente debater estas questões com adultos, não só pela sua experiência de vida, mas também porque é essencial promover a análise crítica neste público-alvo".

- "Achei que o tema é muito interessante e que deveria, em posteriores ações, ser explorado nas suas mais variadíssimas vertentes". 
- "Considero que a formação foi muito pertinente. Gostei das apresentações individuais que nos permitiram contactar com diferentes realidades e abordagens. Sugeria novas formações com abordagens específicas para cada um dos ciclos [de ensino]".

-"A oficina de formação superou as minhas expectativas. Considero-a uma mais-valia para o meu percurso profissional".

- "A temática está na ordem do dia, continua sendo muito necessário transmitir ideias certas e 'claras' às nossas crianças e jovens, para que no mundo haja uma verdadeira igualdade de género".

- "Estes temas devem ser tratados de uma forma mais integrada e integradora, no Projeto Curricular de Turma ou no Projeto Alargado do Agrupamento, com vista a uma educação para a cidadania".

- "[Sugiro] uma maior divulgação nas escolas, pois foi só nesta formação que tivemos conhecimento deste trabalho, pois apesar de os Guiões estarem na Biblioteca Escolar, a comunidade não teve conhecimento de tal facto".

- "A pesquisa em torno desta questão é importante, com vista ao respeito e melhoria das próximas gerações de mulheres (e de homens)".

- "Seria bom que estas atividades fossem à escola".

- "Os Guiões devem ser efetivamente enviados a todas as escolas".

- "[Sugiro] o alargamento destas formações a mais docentes".

\section{Conclusão}

Educar não é um ato neutro e a intencionalidade subjacente ao que se ensina traduz, da parte de quem tem o poder de organizar o ato educativo, a preocupação em trazer para os contextos de 
aprendizagem temas que tornem as pessoas aprendizes, seja qual for a sua idade, capazes de poder gerir as suas vidas, com conhecimentos, mas também com autonomia de pensamento e atitude crítica face ao que as rodeia. Concordamos, por isso, com Freire (2002), quanto ao facto de haver:

uma incompatibilidade total entre o mundo humano da fala, da perceção, da inteligibilidade, da comunicabilidade, da ação, da observação, da comparação, da verificação, da busca, da escolha, da decisão, da rutura, da ética e da possibilidade de sua transgressão e a neutralidade não importa de quê (p. 125).

Educar para a promoção da igualdade entre homens e mulheres deve, nesta sequência, ser uma opção deliberada nos espaços de educação formal e não formal, no âmbito da aprendizagem dos valores de cidadania, o pode acontecer em todas as idades. Para tal torna-se necessária uma intenção política clara de reconhecer à escola um papel central na formação das crianças e jovens, tendo como objetivo o desenvolvimento de valores, de atitudes, de capacidades e de conhecimentos, que as tornem cidadãos e cidadãs participativos/as e críticos/as, tal como preconiza o documento recentemente publicado do Conselho da Europa (2016) sobre as competências para a cultura democrática. Uma escola com estas preocupações necessita de ter um corpo docente e não docente verdadeiramente consciente das responsabilidades partilhadas a este nível, não sendo possível esperar uma atuação condizente com os valores que se defendem, se as práticas, os modelos instituídos e o clima escolar forem contraditórios.

Nesta mesma linha, mas referindo-se em particular a formadores e formadoras de pessoas adultas, Ollangnier (2014) defende que é preciso que sejam capazes de passar primeiro por uma tomada de consciência crítica sobre si e sobre as suas convicções e práticas, 
para depois se sentirem aptos a ultrapassar os seus próprios medos e dificuldades, se quiserem levar quem aprende a "uma tomada de consciência e a alterações de atitudes em matéria de relações sociais de sexo" (p. 221). Este percurso de desenvolvimento pessoal torná-los-ia "gente melhor. Gente mais gente" (Freire 2000, p. 165). Deve, pois, haver um compromisso ético de usar a educação, entendida em sentido lato, como o recurso mais poderoso para a construção de um futuro comum, sendo que a transformação social exige responsabilidade individual. Seja em matéria de combate a desigualdades de género, seja na abolição de outro tipo de discriminações que a estas possam associar-se, o cerne desta mudança reside na capacidade de cada pessoa, de lidar criticamente, mas de forma positiva para si e para os outros, com as condicionantes dos contextos de vida.

\section{Referências bibliográficas}

Amâncio, L. (2002). O género na psicologia social em Portugal: perspetivas atuais e desenvolvimentos futuros, ex aequo, 6, 55-76.

Bem, S. (1993). The lenses of gender: Transforming the debate on sexual inequality. New York: Yale University Press.

Conselho da Europa (2016). Competences for democratic culture. Living together as equals in culturally diverse democratic societies. Disponível em: http://www. coe.int/t/dg4/education/Source/competences/CDC_en.pdf

DGE (2013). Educação para a cidadania - linhas orientadoras. Disponível em: http://www.dge.mec.pt/sites/default/files/ECidadania/educacao_para_cidadania_ linhas_orientadoras_nov2013.pdf

Freire, P. (2000). Pedagogia da autonomia. Saberes necessários à prática educativa (15 ${ }^{a}$ ed.). São Paulo: Paz e Terra.

Freire, P. (2002). Cartas a Cristina Reflexões sobre minha vida e minha práxis. ( $2^{\mathrm{a} e d .) . ~ S a ̃ o ~ P a u l o: ~ E d i t o r a ~ U N E S P . ~}$

Khosla, P. (2008) (Eds.). Gender in local government. A sourcebook for trainers. Nairobi: United Nations Human Settlements Programme. Disponível em: http:// www.un.org/womenwatch/directory/pdf/Source_BK_9-May.pdf

Neves, S. (2015). Pode o género não ser feminista? In A. Torres, H. Sant'Ana, \& D. Maciel (Eds.), Estudos de género numa perspectiva interdisciplinar (pp. 37-46). Lisboa: Editora Mundos Sociais. 
Oakley, A. (1972). Sex, gender, and society. London: Temple Smith.

Ollangnier, E. (2014). Femmes et défis pour la formation des adultes. Un regard critique non-conformiste. Paris: L'Harmattan.

Ostrouch-Kaminska, J., \& Vieira, C. C. (2015) (Eds.). Private world(s). Gender and informal learning of adults. The Nertherlands: Sense Publishers.

Scott, J. A. (1986). Gender: A useful category of historical analysis. The American Historical Review, 91(5), 1053-1075.

Simões, A. (1990). Alguns mitos respeitantes ao idoso. Revista Portuguesa de pedagogia, XXIV, 109-121.

Sprinthall, N. A. \& Collins, W. A. (2011). Psicologia do adolescente. Uma abordagem desenvolvimentista (5ed.). Lisboa: Fundação Calouste Gulbenkian.

Torres, A., Maciel, D., \& Sant'Ana, H. (2015). Introdução. In Torres, H. Sant'Ana, \& D. Maciel (Eds.). Estudos de género numa perspectiva interdisciplinar (pp. 1-6). Lisboa: Editora Mundos Sociais. 